\title{
Great variability in nest lining size: support for thermoregulation but not for anti-predatory adaptation hypothesis
}

\author{
Vojtěch Kubelka ${ }^{1,2,3,4}$ (D) Martin Sládeček ${ }^{5}$ Miroslav Šálek $^{5}$
}

Received: 17 September 2018 / Revised: 21 April 2019 / Accepted: 9 May 2019 / Published online: 27 May 2019

(c) The Author(s) 2019

\begin{abstract}
Nest lining is a key component in nests of many bird species. Among ground-nesting birds with open nests, it usually consists of dry sticks and stalks creating a thermoregulatory insulating layer for the eggs. However, a bigger nest lining can attract predators and increase nest mortality. The factors influencing behavioural plasticity in birds facing the trade-off between nest lining thermoregulation and conspicuousness for predators have remained poorly understood. The Northern Lapwing Vanellus vanellus, a visibly incubating shorebird with an active nest defence against potential predators, demonstrates great variability in the size of nest lining and, at the same time, is subject to a high frequency of nest predation. We analysed the variability of nest-lining size across time and space in 915 measurements of 601 lapwing nests in South Bohemia, Czech Republic, during 2010-2015. We show that lapwing nests placed closer to small water pools with generally cooler microclimates had bigger nest lining. The size of nest linings also reflected the availability of nest lining material in the vicinity of the nest. On the other hand, there was no effect of nest position within the breeding association and distance to the nearest perch as a possible stand for predators on nest lining size. Furthermore, nest lining size did not predict nest predation rate. Our findings suggest that lapwings adjust the size of their nest lining to local microclimate conditions rather than potential predation risk which is in concordance with the thermoregulation hypothesis of the nest size in birds.
\end{abstract}

Keywords Ground-nesting bird $\cdot$ Microclimate $\cdot$ Nest predation $\cdot$ Nest site moisture $\cdot$ Northern lapwing $\cdot$ Shorebirds $\cdot$ Vanellus vanellus

\section{Zusammenfassung}

Hohe Variabilität im Ausmaß der Nestauspolsterung: Belege sprechen für die Thermoregulations-, nicht aber für die Feindvermeidungshypothese.

Die Nestpolsterung ist ein wichtiger Bestandteil der Nester vieler Vogelarten. Bei Bodenbrütern mit offenen Nestern besteht diese normalerweise aus trockenen Stöckchen und Halmen, welche eine thermoregulatorische Isolationsschicht für die Eier bilden. Eine stärkere Nestpolsterung kann jedoch Prädatoren anlocken und somit die Nestlingsmortalität erhöhen. Die Faktoren, welche die Verhaltensplastizität bei Vögeln im Konflikt zwischen thermoregulatorischer Nestpolsterung und der Auffälligkeit für Prädatoren beeinflussen, sind bisher kaum erforscht. Der Kiebitz Vanellus vanellus, eine offen brütende Limikolenart, welche ihre Nester aktiv gegen Prädatoren verteidigt, weist eine starke Variabilität bezüglich des Ausmaßes der Nestpolsterung auf und unterliegt zugleich einer hohen Nestprädationsrate. Wir untersuchten die zeitliche

Communicated by F. Bairlein.

Electronic supplementary material The online version of this article (https://doi.org/10.1007/s10336-019-01670-x) contains supplementary material, which is available to authorized users.

Vojtěch Kubelka

kubelkav@gmail.com

1 Department of Ecology, Faculty of Science, Charles University, Prague, Czech Republic
2 Department of Evolutionary Zoology and Human Biology, Faculty of Science, University of Debrecen, Debrecen, Hungary

3 Department of Biology and Biochemistry, University of Bath, Bath, UK

4 Department of Biodiversity Research, Global Change Research Institute, Czech Academy of Sciences, Brno, Czech Republic

5 Department of Ecology, Faculty of Environmental Sciences, Czech University of Life Sciences, Prague, Czech Republic 
und räumliche Variabilität im Ausmaß der Nestpolsterung anhand von 915 Maßen von 601 Kiebitznestern aus Südböhmen (Tschechische Republik) aus den Jahren 2010-2015. Wir konnten zeigen, dass näher an kleinen Gewässern mit allgemein kühlerem Mikroklima platzierte Kiebitznester stärker ausgepolstert waren. Die Stärke der Nestpolsterung spiegelte außerdem die Verfügbarkeit von Nistmaterial in Nestnähe wider. Andererseits gab es keinen Einfluss der Nestposition innerhalb der Brutgemeinschaft oder des Abstands zur nächsten Sitzwarte als möglichem Ansitz für Prädatoren auf die Stärke der Nestpolsterung. Des Weiteren ließ das Ausmaß der Nestpolsterung keinen Aufschluss auf die Nestprädationsrate zu. Unsere Ergebnisse legen nahe, dass Kiebitze die Stärke ihrer Nestauspolsterung eher an das lokale Mikroklima anpassen als an ein potenzielles Prädationsrisiko, was im Einklang mit der Thermoregulationshypothese der Nestgröße bei Vögeln steht.

\section{Introduction}

The majority of bird species build open cup nests lined with dry plant material and/or soft feathers (Hansell and Deeming 2002; Gill 2007; Deeming and Reynolds 2015). The principal function of the nest lining is thermoregulation of the clutch (Reid et al. 2002; Tulp et al. 2012; Heenan 2013), even though protection of eggs against mechanical damage as well as attracting sexual partners have been suggested to play a role in some species (del Hoyo et al. 1996; Hansell and Deeming 2002; Deeming and Mainwaring 2015; Biddle et al. 2018). Incubation temperature and the amount of heat supplied at certain stages to embryo development may dramatically affect metabolic processes and contribute to the quality of hatchlings (Starck and Ricklefs 1998). Moreover, a bigger nest lining can significantly reduce the energetic costs of incubation faced by adults (Reid et al. 2002; Tulp et al. 2012).

On the other hand, a bigger nest lining with good thermoregulatory function may increase nest detectability for visually oriented predators (Mayer et al. 2009; Mainwaring et al. 2015). Indeed, some studies found that bigger nests are more likely to be depredated in comparison with smaller ones (Grégoire et al. 2003; Antonov 2004; Biancucci and Martin 2010). Therefore, in deciding how to construct their open nest, breeding adults face a trade-off between providing a substantial lining to strengthen the thermoregulatory function of the nest or choosing a scanty lining to reduce the risk of nest predation (Ricklefs 1983; Deeming and Reynolds 2015). This decision may also be influenced by environmental conditions at breeding grounds because, e.g., wetter places tend to have cooler microclimate (e.g. Reid et al. 2002; Rogers et al. 2006; Yang et al. 2013).

Despite decades of intensive research on nest morphology (Deeming and Mainwaring 2015; Mainwaring et al. 2015; Martin et al. 2017), the extent to which individual birds can use environmental cues to fine-tune the morphology of their nest is still unclear (Healy et al. 2015) and further research is needed on how nest size interacts with nest location and parental behaviour (Mainwaring et al. 2015). The aforementioned scenario presents an opportunity to investigate the context of the trade-off between thermoregulation and predation risk, as well as quantify effects of external factors on the behavioural plasticity of individual breeding birds that may have consequences for nesting success, productivity and inevitably species population dynamics.

Nest lining is characteristic for the ground-nesting shorebird, Northern Lapwing (Vanellus vanellus). This species breeds across the Eurasian temperate zone in moderate climates where it builds open nests, predominantly on bare ground with sparse or no vegetation in agricultural landscape (Cramp and Simmons 1983; Nethersole-Thompson and Nethersole-Thompson 1986; Shrubb 2007) and is subject to a high risk of nest predation (e.g. Cramp and Simmons 1983; MacDonald and Bolton 2008a; Roodbergen et al. 2012). High nest predation was recorded also in our target lapwing population in South Bohemia, Czech Republic, where nest position within the breeding association (semicolony or loose colony) may influence the nest predation rate (Šálek and Šmilauer 2002) and visually oriented predators are active (Šálek and Zámečník 2014). Northern Lapwing nest lining size is highly variable, ranging from sparse to very large (Cramp and Simmons 1983; Shrubb 2007) and consists of plant material, predominantly dry stalks of cereals and grasses. The building of each nest continues with the progressive filling of the excavated scrape with plant material, particularly during pre-laying and laying periods by both male and female birds (Cramp and Simmons 1983; Nethersole-Thompson and Nethersole-Thompson 1986; Shrubb 2007) and may thus function as a part of display ritual (Cramp and Simmons 1983). However, environmental factors affecting nest lining size and possible consequences for nest survival are unknown.

The aim of this study is to investigate factors influencing the variability in nest lining size and test whether there is evidence for the thermoregulation or anti-predatory adaptation hypothesis. Specifically, using the Northern Lapwing as the model species, we ask: (1) What is the variability of nest lining size? (2) Which factors (nest site moisture, ambient temperature, position within breeding association, distance to the nearest perch for potential predators, incubation start date, incubation stage and nest linings material availability) predict the nest lining size? Bigger nest linings in wet nesting sites with a cooler microclimate or during spells of lower ambient temperature would represent support for thermoregulation hypothesis, whereas bigger nest linings in the 
middle of the breeding association or further away from the nearest perch for potential predators would suggest influence of anti-predatory adaptation; (3) is a bigger nest lining more obvious for potential predators and does nest predation rate increase with nest lining size?

\section{Materials and methods}

\section{Study area and fieldwork}

We searched for the Northern Lapwing nests in České Budějovice basin in the centre of South Bohemia $\left(49.0^{\circ} \mathrm{N}\right.$, $14.4^{\circ} \mathrm{E}$ ) in the Czech Republic during 2010-2015. The study area consists of circa $60 \mathrm{~km}^{2}$ of agricultural landscape with prevailing arable land of altitude $380-420 \mathrm{~m}$, for more details, see Šálek and Šmilauer (2002) and Zámečník et al. (2018). We searched for nests in areas with breeding lapwings using binoculars and scopes, or direct physical investigation of dense breeding colonies during the breeding season (end of March to end of May).

We recorded nest GPS coordinates and assigned each nest into one of three categories according to habitat structure (Table 1). We determined the start of incubation for each nest with use of the flotation method (van Paassen et al. 1984) or according to known egg-laying sequence [incubation $s t a r t=a$ day when the third egg was laid; Shrubb (2007), for two-egg clutches the date of second egg laying was used]. During every visit, we took a digital picture of the nest from $1 \mathrm{~m}$ directly above the nest with $35-\mathrm{mm}$ optical distance (35-mm lens) to capture the nest and close surroundings up to $1 \mathrm{~m}$ from the nest so as to be able to evaluate the size of the nest lining. During 2014-2015 we also took an additional picture from $2 \mathrm{~m}$ directly above the nest with 35-mm optical distance to capture wider surroundings up to $2 \mathrm{~m}$ from the nest for the purpose of nest lining material availability description. We followed the fate of each nest and determined it as successful (hatched or surviving particular period), depredated or failed for other reason (e.g. agriculture machinery). Every nest where at least one chick hatched was regarded as successful. A hatched nest was recognised according to tiny eggshell fragments remaining in the nest scrape from the hatching process (Green et al. 1987). Clutches with infertile eggs with present parents which had not been depredated over expected egg-laying and incubation period were regarded as successful ones for the purpose of predation analyses. Only complete nest depredations were included in the depredated nests category (partial egg loss were omitted) because partial egg loss does not necessarily mean depredation. While using nest video surveillance, we have repeatedly recorded that egg loss can be the result of accidental egg damage and subsequent eggremoval by incubating parent. Partial egg loss accounts up to $7 \%$ of nests in our lapwing population (own unpublished data). Depredated nests were recognised according to the absence of all eggs before estimated hatching with no marks suggesting another cause of failure or according to remnants of depredated eggs in the nest or close vicinity.

\section{Data processing}

Three authors of this study independently scored nest lining size from digital nest images according to prepared scale into one of eight categories: $0.5-4$ from very sparse to large nest lining (see examples in Fig. 1). The arithmetic mean of these three scores was used for each nest at each nest visit in subsequent analyses. Repeatability among evaluators estimated by function "rpt" (Nakagawa and Schielzeth 2010; Gaussian model) using 1000 bootstraps was $72 \%$ (95\% CI: 69-75\%). To assess whether nest lining size corresponds with nest lining magnitude at the bottom of the nest as an important parameter of thermoregulation capacity, we temporarily removed eggs for a small number of randomly selected nests and carefully measured the nest lining thickness at the bottom of active nests by a vernier calliper (in $\mathrm{mm})$. Indeed, lining thickness strongly correlated with the lining size scored from photographs (Spearman's rank correlation; $r_{\mathrm{s}}=0.78, P<0.001, n=18$ active nests in 2014); therefore, the nest size scored from photographs were used in all analyses as reliable (and for visually oriented predators obvious) predictor of the nest lining magnitude in the bottom as well as at the sides of the nest scrape. Furthermore, V. K. determined the nest site moisture up to $1 \mathrm{~m}$ from the nest with use of digital nest images into three categories 0 -dry nest site (structurally more diversified substrate, small clods separated, light soil); 1 -moist nest site (compacted substrate without small clods, dark soil); 2-open water (pool) present up to $1 \mathrm{~m}$ from the nest. Because the site moisture
Table 1 Habitat categories distinguished in the study

\begin{tabular}{lll}
\hline Category & Description of physiognomy & Crops merged \\
\hline 1 & $\begin{array}{c}\text { Structurally uniform bare field } \\
\text { without or with little vegetation }\end{array}$ & Freshly harrowed or sown spring cereal, maize, bean \\
2 & $\begin{array}{c}\text { Structurally diversified plot without } \\
\text { or with mosaic vegetation }\end{array}$ & Ploughed field, sparsely overgrown fallow, stubble \\
3 & Continuously vegetated areas & Winter cereal, grassland, oilseed, clover \\
\hline
\end{tabular}



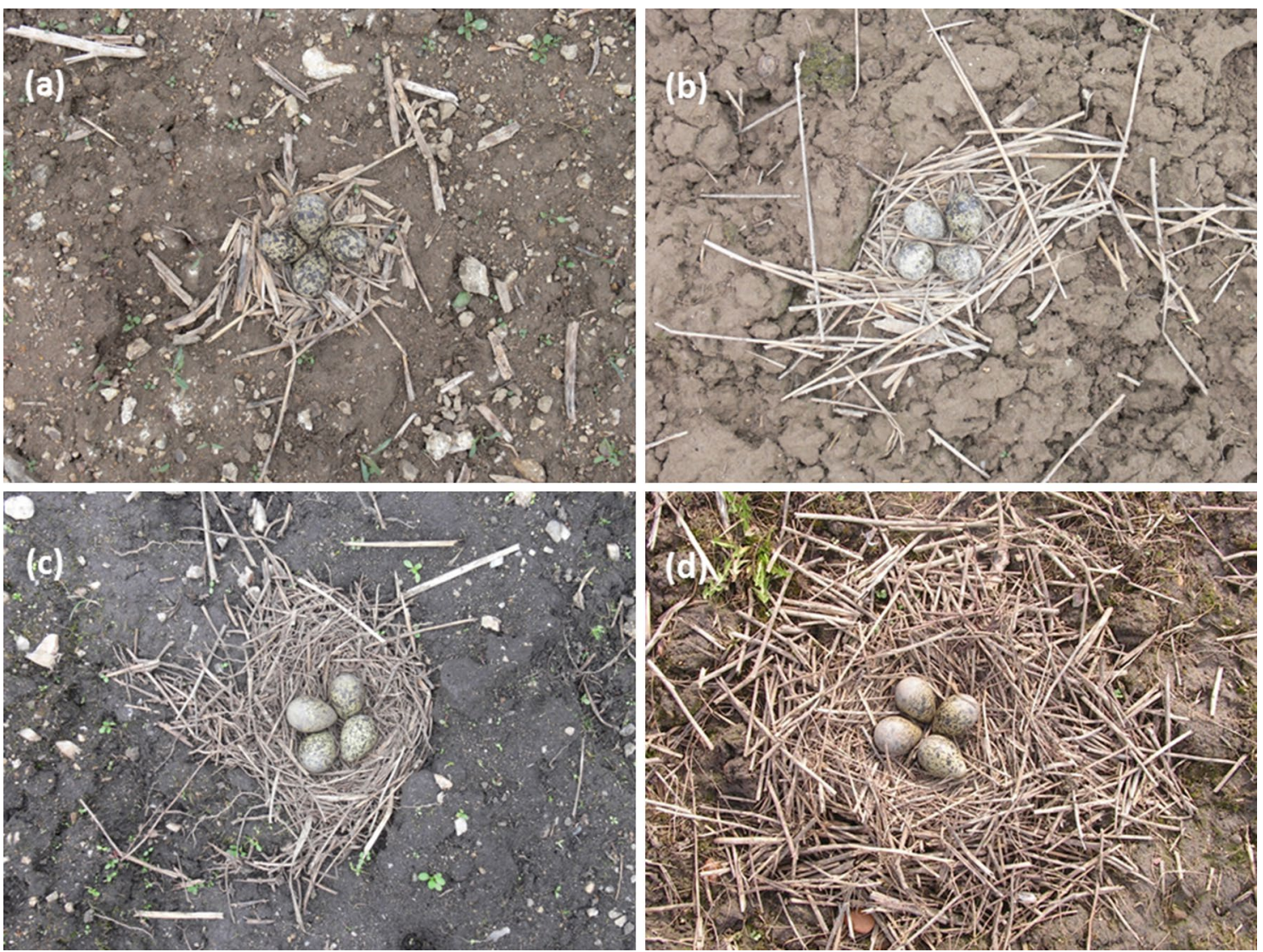

Fig. 1 The scale of Northern Lapwing (Vanellus vanellus) lining size variability. South Bohemia, Czech Republic. Note that these are four examples out of eight possible categories of nest lining size 0.5-4. a Nest with nest lining size scored as 1: sparse nest lining. b Nest with nest lining size scored as 2: obvious nest lining but not meaningfully

extend the nest scrape rim. c Nest with nest lining size scored as 3: distinct nest lining well extended beyond the nest scrape rim. d Nest with nest lining size scored as 4: large nest lining. Photographs credits: a-c Vojtěch Kubelka, d Vladimír Štorek

category was clearly obvious from the picture, only one person was involved in this process. Nest site moisture represented a proxy variable for local microclimate characteristics, where wetter nest sites were supposed to have cooler microclimate (e.g. Reid et al. 2002; Rogers et al. 2006; Yang et al. 2013).

Three independent evaluators (see acknowledgement), without knowledge of study questions and the purpose of the assessment, scored the nest lining material availability around the nests from digital nest images according to a prepared scale into one of three categories 0-2 (Fig. 2). The arithmetic mean of these three scores was further used for each nest at each visit in subsequent analyses. Repeatability estimated by function "rpt" (Nakagawa and Schielzeth 2010) using 1000 bootstraps was 61\% (95\% CI: 55-67\%). Every nesting habitat was assigned into one of three categories according to habitat structure (Table 1).

We evaluated the effect of nest position within the breeding association, known to influence nest predation risk (e.g. Šálek and Šmilauer 2002; MacDonald and Bolton 2008b)

directly on nest lining size. We assigned each nest, according to known nest GPS coordinates, into three following categories of the nest position: (1) solitary nest placed outside of any breeding association (at least $200 \mathrm{~m}$ from the nearest lapwing nest); (2) edge nest creating a convex polygon of all nests present in a breeding association (loose colony) with less than $200 \mathrm{~m}$ distance to the nearest lapwing nest; (3) interior nest placed within the polygon of edge nests in a particular breeding association with less than $200 \mathrm{~m}$ distance to the nearest lapwing nest. Furthermore, with use of the ground distance measurement tool in Google Earth (ver. 7.1), we measured in meters the distance of each nest to the nearest potential perch for avian predators higher than $5 \mathrm{~m}$ (tree, shrub, high stand, building, pole or power lines).

From the given mean daily ambient temperatures in České Budějovice (Czech Hydrometeorological Institute, pers. comm.) at the edge of study area (altitude of $395 \mathrm{~m}$ ), we computed mean ambient temperature value in ${ }^{\circ} \mathrm{C}$ from 5 days prior the day of incubation start (excluded) to estimate the general harshness of environmental conditions in 

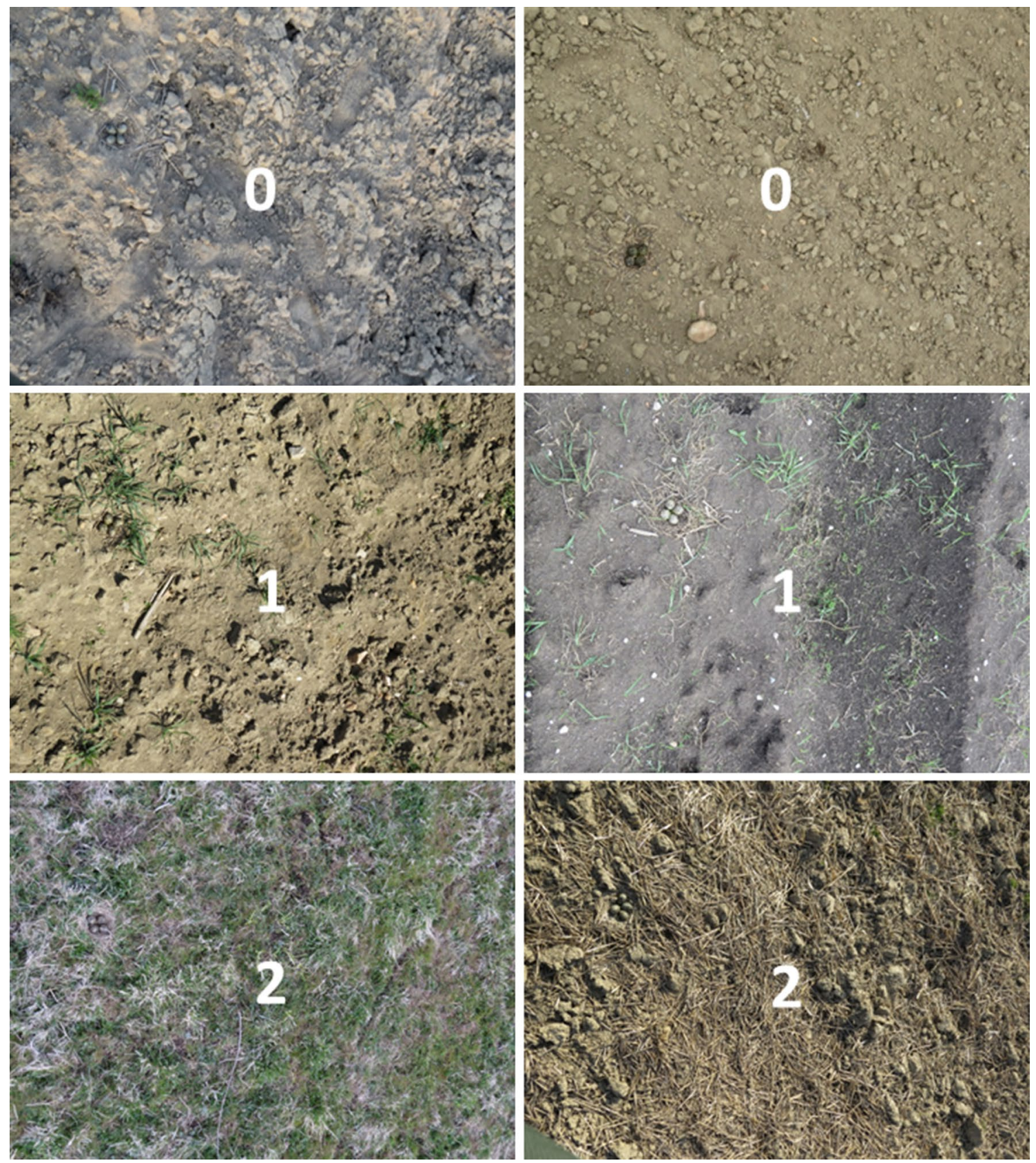

Fig. 2 The scale for nest lining material availability in the vicinity of the nest. (0) nothing or a little; (1) sort of; (2) plenty. Photographs credit: Vojtěch Kubelka

our study area just before and during the egg laying when lapwings predominantly build the nest lining (Cramp and Simmons 1983).

In order to evaluate, whether nest lining size regardless the nest surrounding affects visibility of nests to potential predators in the visible (light) part of electromagnetic spectrum, we conducted experimental enlargement or reduction of nest lining size using ten real nests with big nest lining size and ten nests with small nest lining size. Photographs were taken in 2010 from a height on a 3-m telescopic pole and nests were randomly situated out of the picture centre. Nest lining was then virtually manipulated on photographs in the software GIMP-2.6.12 using the default cloning function (selective copying using a brush). On each rich-lined nest photo, the majority of the nest lining was covered with small areas selected from the surroundings of the particular nest so that only a clutch with heavily reduced lining remained. In contrast, the lining of the poorly lined nests was virtually enlarged spreading around several small portions of lining up to 
the large nest lining size. With this virtual manipulation, a total of 40 nest photos were obtained, of which twenty with large nest lining size and twenty with small nest lining size (half of them manipulated and half of them as control nests in each group). The nests were randomly sorted in the questionnaire so that respondents (not informed in advance about the manipulation and thus unable to distinguish the relationships among the pictures) were asked to score each nest into one of four categories of nest conspicuousness (1: inconspicuous, 2: visible, 3 : conspicuous, 4: strikingly visible), considering also the time needed to locate the nest on the picture. Ten original nests with big nest lining size had mean evaluation of 57 respondents 3.4 and ten nests with small nest lining size 1.9. The final scores of 57 respondents evaluating nest visibility were repeatable with 51\% (95\% CI: 38-61\%).

We computed daily nest predation rates according to Mayfield, defined as the number of depredated nests divided by the exposure of all nests in days (Mayfield 1961, 1975). The procedure of computing the exposure for daily nest predation was conducted following Kubelka et al. (2018). The exposure for hatched nests is from the day of finding until known or predicted hatching (e.g. 11 April and 28 April means $28-11=17$ days of exposure). The exposure for depredated nests lasted from the day of finding until midpoint assumption between last positive and first negative visits of the particular nest, the exposure for failed nests due to any other reason than predation (e.g. agriculture machinery, nest abandonment). For nests with an unidentified fate the exposure lasted from the day of finding until the last positive visit only.

\section{Statistical analyses}

Statistical analyses were performed with R, ver. 3.3.3 (R Development Core Team 2017). We used linear mixedeffect models (LME), fitted with the "Imer" function from the "Ime4" package (Bates et al. 2015) controlling for all remaining predictors in the model-type III analysis and with a random intercept of the year and locality. Assumptions of models (e.g. normality and homoscedasticity of residuals) were checked visually from diagnostic plots (Crawley 2013). We used the "mixed" function from the "afex" package (Singmann et al. 2018) for $P$ values computation. We compared individual categories of nest site moisture and nest lining material availability by post hoc multiple comparisons of means (Tukey contrasts) in the "multcomp" package (Hothorn et al. 2017). We used paired $t$ tests for virtual manipulation of nest lining size and generalized linear mixed model (GLMM) with binomial error structure, logit link function and random factor of locality in the analysis of relationship between daily nest predation rate and nest lining size. All tests were two-tailed.

\section{Results}

\section{Nest lining size variability}

Nest lining in the given lapwing population was highly variable, ranging between 0.5 and 4 of the mean score, mean $=1.91 \pm 0.63(\mathrm{SD})$, median $=1.83$ and within a reasonable range of 1-25 days of incubation stage it is slightly decreasing over the incubation period (Fig. 3; LME: $F_{1,332}=50.16, P<0.001$, random factors: year, locality and nest 817 measurements of 557 nests). However the incubation stage did not influence nest lining size in the first measurements of each nest (LME: $F_{1,550}=1.00, P=0.320$, random factors: year and locality 557 measurements of 557 nests), used in further analyses.

\section{Factors affecting nest lining size}

Nest lining size was significantly influenced by nest site moisture and availability of nest lining material (Table 2). Breeding habitat was no longer significant after controlling for the availability of nest lining material. Ambient temperature, incubation start date, incubation stage, position in the breeding association and distance to the nearest perch for potential predators were non-significant predictors of nest lining size. Nest lining size was found to be bigger in wetter nest sites (Fig. 4, Table 2) with the following mean nest lining score values: Dry $=1.69$, Moist $=2.05$, Water $=2.46$ (all categories significantly different: Tukey contrasts; $z$ values $=4.79-8.38 ; P$ always $<0.001 ; n=557$ nests). Nest lining size was found to be bigger at sites with higher nest lining material availability (Fig. 5, Table 2).

\section{Nest visibility and predation rate}

Virtual removal of rich nest lining led to a significant decrease of nest visibility (with a change of mean score from 3.4 to 2.0 and the difference in particular nests $1.37 \pm 0.16$; paired $t$ test; $t=8.15, d f=9, P<0.001)$, representing a mean drop from $84 \%$ to $50 \%$ of the maximum score (4: strikingly visible). Similarly, the virtual enrichment of poor lining led to a significant increase in nest visibility (change of mean score from 1.9 to 2.9 and the difference in particular nests $1.00 \pm 0.14$; paired $t$ test; $t=6.72, d f=9, P<0.001)$, representing an increase from $46 \%$ to $71 \%$ of the maximum score. Nest lining size did not predict daily nest predation rate $\left(\mathrm{GLMM}_{\text {binomial }}, z=0.60, P=0.552, n=590\right.$ nests during 2010-2015). 
Fig. 3 Nest lining size variability during incubation. Size of the dots reflects the sample size, error bars $=\mathrm{SE}, \mathrm{n}=915$ measurements of 601 lapwing nests from 2010-2015 in South Bohemia, Czech Republic. See Methods for scoring procedure and Fig. 1 for nest lining size category examples

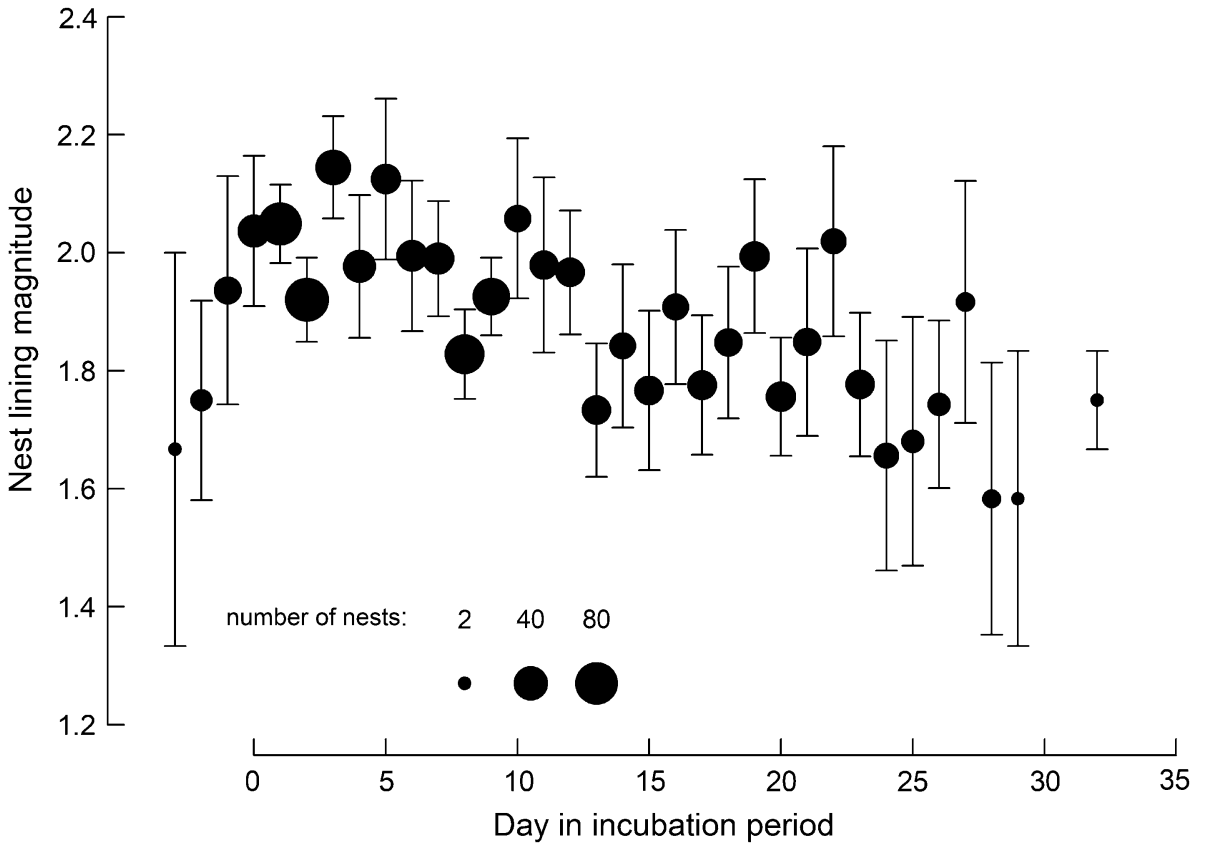

Table 2 Effect of nest site moisture, nest lining material availability, breeding habitat, ambient temperature, incubation start date, position in the breeding association and distance to the nearest perch for potential predators on nest lining size in South Bohemia, Czech Republic

\begin{tabular}{llrr}
\hline Predictor & $d f$ & \multicolumn{1}{l}{ F } & \multicolumn{1}{l}{$P$} \\
\hline (a) Whole dataset 557 nests & & & \\
Nest site moisture & $2 ; 249$ & 28.88 & $<0.001$ \\
Breeding habitat & $2 ; 184$ & 17.72 & $<0.001$ \\
Incubation stage & $1 ; 543$ & 2.35 & 0.130 \\
Ambient temperature & $1 ; 400$ & 2.09 & 0.150 \\
Incubation start date & $1 ; 84$ & 0.46 & 0.500 \\
(b) Reduced dataset 418 nests & & & \\
Nest site moisture & $2 ; 216$ & 17.13 & $<0.001$ \\
Breeding habitat & $2 ; 197$ & 9.11 & $<0.001$ \\
Position in the association & $2 ; 404$ & 0.49 & 0.610 \\
Distance to the perch & $1 ; 195$ & 0.14 & 0.710 \\
(c) Reduced dataset 206 nests & & & \\
Nest lining material availability & $1 ; 182$ & 21.07 & $<0.001$ \\
Nest site moisture & $2 ; 198$ & 4.97 & 0.008 \\
Breeding habitat & $2 ; 110$ & 1.40 & 0.250 \\
\hline
\end{tabular}

Linear mixed effect model with the random effect of year and locality, all predictors were controlled for the effect of remaining ones-type III analysis. All significant predictors are kept in subsequent models. (a) $n=557$ nests during 2010-2015. (b) $n=418$ nests during 20112015 with measured position in the breeding association and distance to the perch. (c) $n=206$ nests during 2014-2015 with measured nest lining material availability. We used "mixed" function from 'afex' package (Singmann et al. 2018) for $P$ values computation. See Methods for more details and Table 1 for habitat descriptions

\section{Discussion}

We have shown that Northern Lapwing nest lining size was influenced by nest site wetness and nest lining material availability but not affected by ambient temperature, incubation start date, incubation stage, nest position within the breeding association or nest distance to the nearest perch for potential predators. The effect of breeding habitat was likely driven by a higher nest lining material availability (see more details in Supplementary Appendix). Furthermore, we have shown that the nest lining size does not predict the daily nest predation.

Nests with bigger linings were found at wetter nest sites, especially when an open water pool was closer that one meter from the nest and nest site moisture served as a proxy for local microclimate. Our finding is in line with general assumption that thermoregulatory function of the nest is important (Deeming and Reynolds 2015), especially in ground-nesting species breeding in the extreme climates of Arctic (Tulp et al. 2012) or alpine environments (Camfield and Martin 2009). Thus, Arctic shorebirds prefer to breed on slopes with a milder microclimate (Meltofte et al. 2007) and use specific lining material to reduce heat loss from nests (Reid et al. 2002). Detailed studies on nest design of the Pectoral Sandpiper (Calidris melanotos) from areas with permafrost confirmed that the birds reduce the rate of heat loss from the nests using the lining of nest scrapes and that deeper nest cups are more effective in heat retention (Reid et al. 2002). We may assume that just a specific layer of dry stalks containing sufficiently large air cells has effective insulating function against environmental harshness (Deeming and Mainwaring 2015) and could play an important role 
Fig. 4 Lining nest size relationship with nest site moisture (a) and breeding habitat (b). Box-plots represent two decades before and six decades after the median of incubation start each year. Medians with $95 \%$ CI (notches), quartiles, 1.5 inter-quartile range and outliers are presented, $n$ size $=557$ nests during 2010-2015 in South Bohemia, Czech Republic, particular sample sizes in number of nests are follows: Dry $=201$, Moist $=296$, Water $=60$,

Bare $=186$, Diversified $=212$, Vegetated $=159$, for more details see Table 1

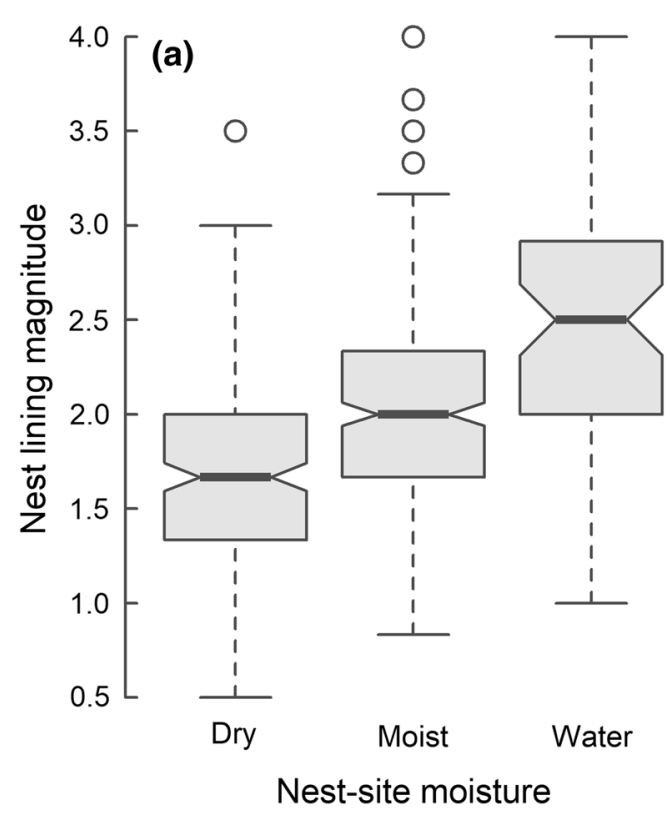

Fig. 5 Effect of nest lining material availability on nest lining size in 206 nests from 2014 and 2015. Line with shaded area indicate model prediction with 95\% credible intervals based on the joint posterior distribution of 5000 simulated values based on model outputs (Table 2) and generated by the "sim" function in R (Gelman et al. 2016)

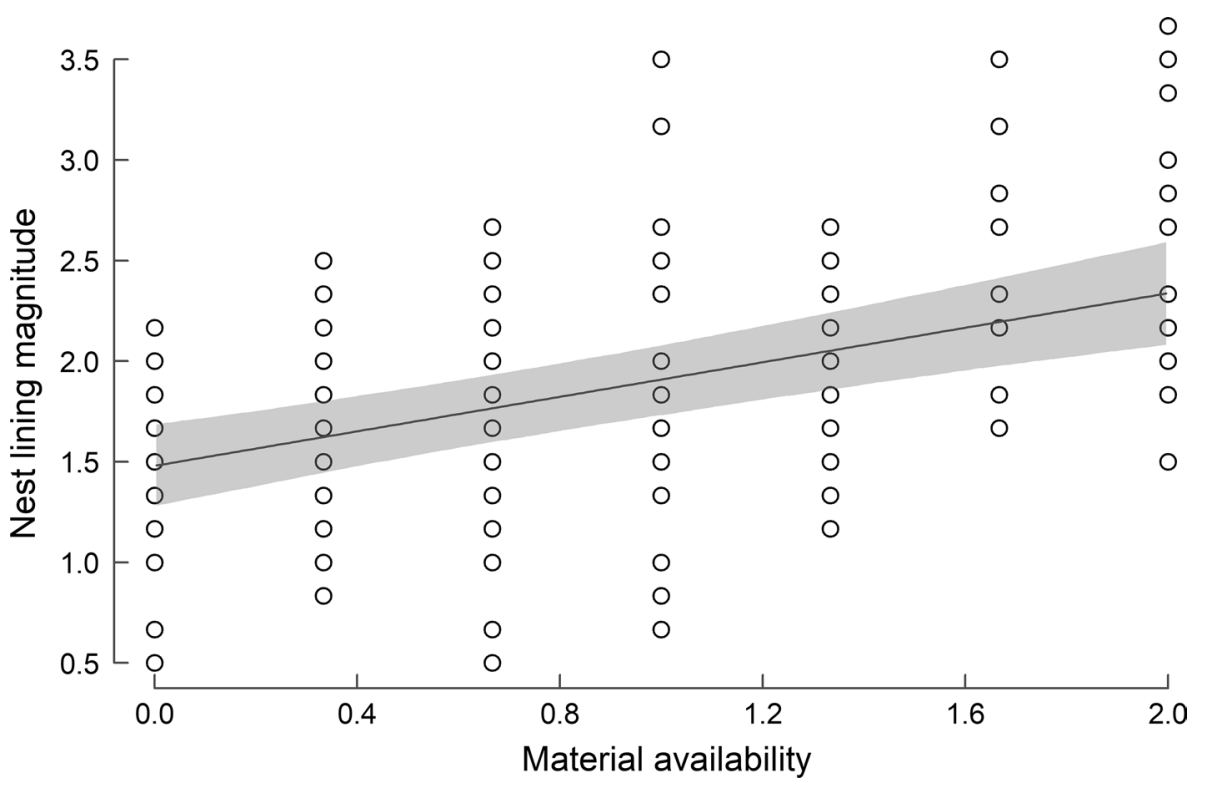

also for shorebird species breeding in temperate agricultural landscape, particularly in wet places with cooler microclimate (e.g. Reid et al. 2002; Rogers et al. 2006; Yang et al. 2013). No effect of ambient temperature on nest lining size suggests that from the egg insulation perspective, the local microclimate (nest site moisture) plays a more important role than average ambient temperatures over the whole study area. It is important to note that we used the nest site moisture as a proxy variable to characterise the local nest microclimate and direct temperature measurements in the nest surroundings could provide more precise information.

Nest lining size was bigger at places with a higher availability of nest lining material. This finding is not surprising given the fact that nest lining behaviour performed by both parents can be a part of display ritual in lapwings (Cramp and Simmons 1983; Nethersole-Thompson and NethersoleThompson 1986; Shrubb 2007). This display can be partially ritualized-done also without plant material (Cramp and Simmons 1983); therefore, display intensity does not have to be more intense at sites with more nest lining material availability, but could be more ritualized at the sites with less nest lining material availability. Thus, lapwings are simply using plant material more when it is available in the nest surrounding, which is the case, especially in more vegetated nesting habitat. Similarly, Piping Plovers (Charadrius melo$d u s$ ) used more shell fragments in their nest lining when the 
nest was located on shelly, rocky, or coarse-sanded beaches (Greenwald 2009). Generally, bird nest lining composition often reflects the nest lining material (quality and quantity) available during nest building (Deeming and Mainwaring 2015). Alternativelly, breeding birds could afford bigger nest lining at the places with more nest lining material, because such nests are not so obvious for potential predators in this heterogeneous surrounding (Stevens et al. 2017; Gómez et al. 2018). Disentangling these explanations would need experimental nest lining size manipulation.

While bigger nests are more obvious for potential predators (Grégoire et al. 2003; Antonov 2004; Biancucci and Martin 2010), visually oriented predators are active at lapwing breeding grounds in our study (Šálek and Cepáková 2006; Šálek and Zámečník 2014) and nest lining size was revealed as important factor in determining conspicuousness of lapwing nests for visually oriented predators, there was no significant effect of nest position within the breeding association or nest distance to the nearest perch for potential predators on the nest lining size and no effect of the nest lining on daily nest predation rate. These findings can have several not mutually exclusive explanations: (1) breeding Northern Lapwings are known as aggressive nest defenders (Elliot 1985; Liker and Székely 1999; Kis et al. 2000) and thus can effectively repel potential avian predators from breeding grounds, and therefore, they are not forced to make the nest lining smaller under higher risk or depredation, e.g. nest placement close to perches for predators or outside of the breeding association (Šálek and Šmilauer 2002, MacDonald and Bolton 2008b); (2) visually oriented predators play a minor role in our study population where predominantly mammals, especially Red Fox (Vulpes vulpes) and Stone Marten (Martes foina), were recognized as nest predators (Kubelka 2015, own unpublished data); iii) nest lining size per se could not be the important clue for visually oriented predators during nest search, but rather other stimuli, e.g. visibility of incubating parent (Šálek and Zámečník 2014) could play more important role for nest predation risk. Although a bigger nest lining renders lapwing's nest more obvious for potential predators, some ground nesting birds may enhance the crypsis of their eggs by enlarging the stony nest lining (Goméz et al. 2018), therefore the visibility of nests for potential predators should be assessed for each species separately.

The presented study provides several insights into the longstanding debate on the trade-off between nest size thermoregulatory function and conspicuousness for predators (Ricklefs 1983; Deeming and Reynolds 2015). First, using large sample sizes over 6 years, we show that lapwings may adjust their nest lining size to the local microclimate, building larger nest linings in wetter nest locations, thus providing support for thermoregulatory functions of the nest lining. Second, nest lining material availability is also a significant predictor of nest lining size and effects of both predictors can be additive.
Third, nest lining size is not adjusted to presumed nest predation risk and it does not predict nest predation rate, suggesting that lapwings with active defence of their nests are not forced to reduce nest lining size as the anti-predatory adaptation.

Acknowledgements Open access funding provided by University of Debrecen (DE). We thank E. Zoubková and V. Štorek for essential help with the data collection and A. Timrová, V. Kutišová and O. Kubelka for the assessment of nest lining material availability. Furthermore, we thank R. Piálková, Z. Karlíková, M. Nacházelová, J. Vlček and K. Chmel for regular help in the field and V. Dočekalová, D. Kubelková and K. Mášková for help with data transcription into the primary database. We thank Czech Hydrometeorological Institute for ambient temperature data. T. Albrecht and two anonymous referees helped us with their critical comments on the previous version of the manuscript. We thank G. C. McDonald from University of Oxford for the English improvement. V.K. was supported by the Charles University Grant Agency (GAUK 927516), ÉLVONAL-KKP 126949 of the Hungarian government and Ministry of Education, Youth and Sports of Czech Republic (grant No. LO1415). M.S. and M.Š. were supported by IGA FŽP (project No. 20174231), CIGA (project No. 20164209) and IGA FŽP (project No. 20164218) grants. There is no conflict of interest in the publication of this manuscript for any author. All authors conceived and planned the study, VK and MS collected the data with the help from MŠ, all authors analysed the data, VK was the lead writer of the manuscript with input from MS and MŚ. This study complies with all Czech and European laws and adheres to appropriate ethical standards. Data and R codes for study are available at Open Science Framework (https://ofs.io/jnvf8/files/).

Open Access This article is distributed under the terms of the Creative Commons Attribution 4.0 International License (http://creativeco mmons.org/licenses/by/4.0/), which permits unrestricted use, distribution, and reproduction in any medium, provided you give appropriate credit to the original author(s) and the source, provide a link to the Creative Commons license, and indicate if changes were made.

\section{References}

Antonov A (2004) Smaller Eastern Olivaceous Warbler Hippolais pallida elaeica nests suffer less predation than larger ones. Acta Ornithol 39:87-92. https://doi.org/10.3161/0001645044213884

Bates D, Mächler M, Bolker B, Walker S (2015) Fitting linear mixedeffects models using lme4. J Stat Softw 67:1-48. https://doi. org/10.18637/jss.v067.i01

Biancucci L, Martin TE (2010) Can selection on nest size from nest predation explain the latitudinal gradient in clutch size? J Anim Ecol 79:1086-1092. https://doi.org/10.111 $1 / \mathrm{j} .1365-2656.2010 .01720 . x$

Biddle LE, Deeming DC, Goodman AM (2018) Birds use structural properties when selecting materials for different parts of their nests. J Ornithol 159:999-1008. https://doi.org/10.1007/s10336-018-1571-y

Camfield AF, Martin K (2009) The influence of ambient temperature on horned lark incubation behaviour in an alpine environment. Behaviour 146:1615-1633. https://doi.org/10.1163/156853909X463335

Cramp S, Simmons KEL (1983) Handbook of the birds of Europe, the Middle East, and North Africa: the birds of the Western Palearctic, Volume III: Waders to Gulls. Oxford University Press, Oxford Crawley MJ (2013) The R book, second. Wiley, Chichester

Deeming DC, Mainwaring MC (2015) Functional properties of nests. In: Deeming DC, Reynolds SJ (eds) Nests, eggs, \& 
incubation-new ideas about avian reproduction. Oxford Univeristy Press, Oxford, pp 29-49

Deeming DC, Reynolds SJ (eds) (2015) Nests, eggs, and incubation. New ideas about avian reproduction. Oxford Univeristy Press, Oxford

del Hoyo J, Elliott A, Sargatal J (eds) (1996) Handbook of the birds of the world. Hoatzin to Auks, vol 3. Lynx Edicions, Barcelona

Elliot RD (1985) The exclusion of avian predators from aggregations of nesting lapwings (Vanellus vanellus). Anim Behav 33:308-314

Gelman A, Su Y-S, Yajima M, et al (2016) Data Analysis Using Regression and Multilevel/Hierarchical Models. CRAN Repos. 1-53

Gill FB (2007) Ohnithology. W. H. Freeman and Company, New York

Gómez J, Ramo C, Troscianko J et al (2018) Individual egg camouflage is influenced by microhabitat selection and use of nest materials in ground-nesting birds. Behav Ecol Sociobiol 72:142. https://doi. org/10.1007/s00265-018-2558-7

Green RE, Hawell J, Johnson TH (1987) Identification of predators of wader eggs from egg remains. Bird Study 34:87-91. https://doi. org $/ 10.1080 / 00063658709476940$

Greenwald KR (2009) Nest nining and fledging success in the Piping Plover are related to nest site characteristics. Waterbirds 32:464 467. https://doi.org/10.1675/063.032.0314

Grégoire A, Garnier S, Dréano N, Faivre B (2003) Nest predation in Blackbirds (Turdus merula) and the influence of nest characteristics. Ornis Fenn 80:1-10

Hansell MH, Deeming DC (2002) Locacion, structure and function of incubating sites. In: Deeming DC (ed) Avian incubation. Behaviour, environment and evolution. Oxford Univeristy Press, New York, pp 8-27

Healy SD, Morgan KV, Bailey IE (2015) Nest construction behaviour. In: Deeming DC, Reynolds SJ (eds) Nests, eggs, \& incubationnew ideas about avian reproduction. Oxford Univeristy Press, Oxford, pp 16-28

Heenan CB (2013) An overview of the factors influencing the morphology and thermal properties of avian nests. Avian Biol Res 6:104-119. https://doi.org/10.3184/003685013X13614670646299

Hothorn T, Bretz F, Westfall P, et al (2017) Package 'multcomp' R Package Version 1.4-8. https://cran.r-project.org/web/packages/ multcomp/multcomp.pdf

Kis J, Liker A, Szekely T (2000) Nest defence by Lapwings: observations on natural behaviour and an experiment. Ardea 88:155-163

Kubelka V (2015) Northern Lapwing Vanellus vanellus - presence in South Bohemia. In: Kloubec B, Hora J, Šlastný K (eds) Birds of South Bohemia. Jihočeský Kraj, České Budějovice, pp 221-223

Kubelka V, Šálek M, Tomkovich P, Végvári Z, Freckleton RP, Székely $\mathrm{T}$ (2018) Global pattern of nest predation is disrupted by climate change in shorebirds. Science 362:680-683. https://doi. org/10.1126/science.aat 8695

Liker A, Székely T (1999) Parental behaviour in the Lapwing Vanellus vanellus. Ibis 141:608-614

MacDonald MA, Bolton M (2008a) Predation on wader nests in Europe. Ibis 150:54-73

MacDonald MA, Bolton M (2008b) Predation of Lapwing Vanellus vanellus nests on lowland wet grassland in England and Wales: effects of nest density, habitat and predator density. J Ornithol 149:555-563

Mainwaring MC, Reynolds SJ, Weidinger K (2015) The influence of predation on the location and desing of nest. Nests, eggs, \& incubation-new ideas about avian reproduction. Oxford Univeristy Press, Oxford, pp 50-64

Martin TE, Boyce AJ, Fierro-calder K et al (2017) Enclosed nests may provide greater thermal than nest predation bene fi ts compared with open nests across latitudes. Funct Ecol 31:1231-1240. https ://doi.org/10.1111/1365-2435.12819

Mayer PM, Smith LM, Ford RG et al (2009) Nest construction by a ground-nesting bird represents a potential trade-off between egg crypticity and thermoregulation. Oecologia 159:893-901
Mayfield H (1961) Nesting success calculated from exposure. Wilson Bull 73:255-261

Mayfield HF (1975) Suggestions for calculating nest success. Wilson Bull 87:456-466

Meltofte H, Piersma T, Boyd H et al (2007) Effects of climate variation on the breeding ecology of Arctic shorebirds-Meddelelser om Grønland Bioscience 59. Danish Polar Center, Copenhagen

Nakagawa S, Schielzeth H (2010) Repeatability for Gaussian and nonGaussian data: a practical guide for biologists. Biol Rev Camb Philos Soc 85:935-956. https://doi.org/10.1111/j.1469-185X.2010.00141.x

Nethersole-Thompson D, Nethersole-Thompson M (1986) Waderstheir breeding, haunts and watchers. T \& A D Poyser, Calton

R Development Core Team (2017) R: A language and environment for statistical computing. Vienna, Austria. https://cran.r-project.org

Reid JM, Cresswell W, Holt S et al (2002) Nest scrape design and clutch heat loss in Pectoral Sandpipers (Calidris melanotos). Funct Ecol 16:305-312

Ricklefs RE (1983) Comparative avian demography. In: Johnston RF (ed) Current ornithology. Plenum Press, New York, pp 1-32

Rogers DI, Battley PF, Piersma T et al (2006) High-tide habitat choice: insights from modelling roost selection by shorebirds around a tropical bay. Anim Behav 72:563-575. https://doi.org/10.1016/j. anbehav.2005.10.029

Roodbergen M, van der Werf B, Hötker H (2012) Revealing the contributions of reproduction and survival to the Europe-wide decline in meadow birds: review and meta-analysis. J Ornithol 153:53-74. https://doi.org/10.1007/s10336-011-0733-y

Šálek M, Cepáková E (2006) Do northern lapwings Vanellus vanellus and little ringed plovers Charadrius dubius rely on egg crypsis during incubation? Folia Zool 55:43-51

Šálek M, Śmilauer P (2002) Predation on Northern Lapwing Vanellus vanellus nests: the effect of population density and spatial distribution of nests. Ardea 90:51-60

Šálek M, Zámečník V (2014) Delayed nest predation: a possible tactic toward nests of open-nesting birds. Folia Zool 63:67-72. https:// doi.org/10.25225/fozo.v63.i2.a3.2014

Shrubb M (2007) The Lapwing. T \& A D Poyser, London

Singmann H, Bolker B, Westfall J et al (2018) Package 'afex'. https:// cran.r-project.org/web/packages/afex/afex.pdf

Starck JM, Ricklefs RE (eds) (1998) Avian growth and development. Evolution within the altricial-precocial spectrum. Oxford Univeristy Press, New York

Stevens M, Troscianko J, Wilson-Aggarwal JK, Spottiswoode CN (2017) Improvement of individual camouflage through background choice in ground-nesting birds. Nat Ecol Evol 1:13251333. https://doi.org/10.1038/s41559-017-0256-x

Tulp I, Schekkerman H, de Leeuw J (2012) Eggs in the freezer: energetic consequences of nest site and nest design in Arctic breeding shorebirds. PLoS One 7:e38041. https://doi.org/10.1371/journ al.pone. 0038041

van Paassen AG, Veldman DH, Beintema AJ (1984) A simple device for determination of incubation stages in eggs. Wildfowl $35: 173-178$

Yang X, Zhao L, Bruse M, Meng Q (2013) Evaluation of a microclimate model for predicting the thermal behavior of different ground surfaces. Build Environ 60:93-104. https://doi.org/10.1016/j.build env.2012.11.008

Zámečník V, Kubelka V, Šálek M (2018) Visible marking of wader nests to avoid damage by farmers does not increase nest predation. Bird Conserv Int 28:293-301. https://doi.org/10.1017/S0959 270916000617

Publisher's Note Springer Nature remains neutral with regard to jurisdictional claims in published maps and institutional affiliations. 